\title{
Performance of Heat Transfer Correlations Adopted at Supercritical Pressures: A Review
}

\author{
Edward Shitsi*, Seth Kofi Debrah, Vincent Yao Agbodemegbe, Emmanuel Ampomah-Amoako \\ Department of Nuclear Engineering, Graduate School of Nuclear and Allied Sciences, \\ University of Ghana, Accra, Ghana \\ Email: *edwardshitsi@ya hoo.com, s.debrah@gaecgh.org, vincevalt@gmail.com, emmagaec@gmail.com
}

How to cite this paper: Shitsi, E., Debrah, S.K., Agbodemegbe, V.Y. and Ampomah-Amoako, E. (2018) Performance of Heat Transfer Correlations Adopted at Supercritical Pressures: A Review. World Journal of Engineering and Technology, 6, 241-267.

https://doi.org/10.4236/wjet.2018.62014

Received: March 20, 2018

Accepted: May 7, 2018

Published: May 10, 2018

Copyright ( $) 2018$ by authors and Scientific Research Publishing Inc. This work is licensed under the Creative Commons Attribution International License (CC BY 4.0).

http://creativecommons.org/licenses/by/4.0/

\begin{abstract}
Research activities involving heat transfer at supercritical pressures have attracted attention in recent years because of possibility of increase in thermal output of heat transfer and industrial equipment. Because of high pressure and temperature conditions associated with heat transfer at supercritical pressures, only few experimental heat transfer studies are being carried out at supercritical conditions. The use of numerical tools for heat transfer and other related studies at supercritical pressures is increasing because of the high-pressure-temperature limitation of experimental studies at supercritical conditions. Heat transfer correlations implemented in these numerical tools are used to obtain numerical heat transfer data to complement experimental heat transfer data provided through experimental studies. In order to further broaden the understanding of fluid flow and heat transfer, this review examines the performance of heat transfer correlations adopted at supercritical pressures. It is found from the review that most of the correlations could predict heat transfer quite well in the low enthalpy region and few of the correlations could predict heat transfer in the high enthalpy region near critical and pseudo-critical conditions (heat transfer deteriorated conditions). However, no single heat transfer correlation is able to accurately predict all the experimental results presented in this work.
\end{abstract}

\section{Keywords}

Heat Transfer Correlations, Supercritical Pressure, Heat Transfer Deterioration, Supercritical Water Cooled Reactor SCWR

\section{Introduction}

The knowledge of heat transfer phenomena and prediction methods for heat transfer at supercritical pressure conditions are required for the design and op- 
eration of Supercritical Water Cooled Reactor SCWR. Gathering knowledge available on work done so far relating to heat transfer and prediction methods at supercritical pressure conditions is necessary and important for future research needs towards the development of SCWR. Supercritical pressure conditions of water include conditions above critical pressure and temperature of $22.1 \mathrm{MPa}$ and $373.9^{\circ} \mathrm{C}$ respectively.

Research to understand and apply heat transfer at supercritical pressures in various industrial applications including power engineering, aerospace engineering, chemical engineering, cryogenics, and refrigeration engineering have been performed since 1950's [1] [2] [3]. The most used fluids are water, carbon dioxide and helium. Refrigerant R-134a is also being considered due to its lower critical parameters compared to water [4] [5]. This work which focuses on review of studies carried out in predicting heat transfer at supercritical pressures mainly considered heat transfer in water. Effort was made to understand heat transfer phenomenon at supercritical pressures by explaining some terms associated with heat transfer at supercritical pressures. These terms include Normal Heat Transfer (NHT), Improved or Enhanced Heat Transfer (IHT or EHT), and Deteriorated Heat Transfer (DHT). The NHT, IHT and DHT are three major heat transfer regimes that can be noticed at critical and supercritical pressures [6] [7].

1) Normal Heat Transfer (NHT) can be characterised in general with wall heat transfer coefficients similar to those of subcritical convective heat transfer far from the critical or pseudocritical regions, when calculated according to the conventional single-phase Dittus-Boelter-type correlations: $\mathrm{Nu}=0.0023 \mathrm{Re}^{0.8} \mathrm{Pr}^{0.4}$ (Figure 1(a) and Figure 1(b)). In addition, in this regime, the bulk fluid temperature is below the pseudo-critical temperature. Heat Transfer from a test section is quantitatively determined by determining the values of HTC [6].

2) Improved or Enhanced Heat Transfer (IHT or EHT) is characterised with higher values of the wall heat transfer coefficient compared to those at the normal heat transfer; and hence lower values of wall temperature within some part of a test section or within the entire test section (Figure 1(a)). The improved heat-transfer regime or mode includes peaks or "humps" in the heat transfer coefficient near the critical or pseudo-critical points [6].

3) Deteriorated Heat Transfer (DHT) is characterized with lower values of the wall heat transfer coefficient compared to those at the normal heat transfer; and hence has higher values of wall temperature within some part of a test section or within the entire test section (Figure 1(b) and Figure 1(c)). In general, deviations from normal heat transfer have been found to occur when the wall temperature is greater than the pseudo-critical temperature and the bulk temperature is less than the pseudo-critical temperature $\left(T_{w}>T_{p c}>T_{b}\right)$, and the heat flux is above a certain value, depending on the flow rate and the pressure [6].

It is known from the existing literature that buoyancy effect and bulk flow acceleration effect are mechanisms responsible for HTD as a result of the extent of variation of thermophysical properties at supercritical pressures [8] [9] [10]. The 


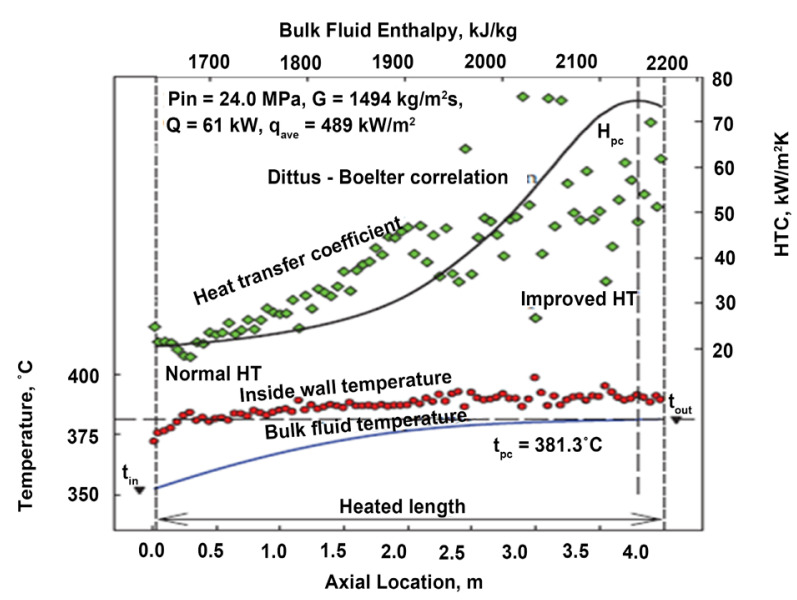

(a)

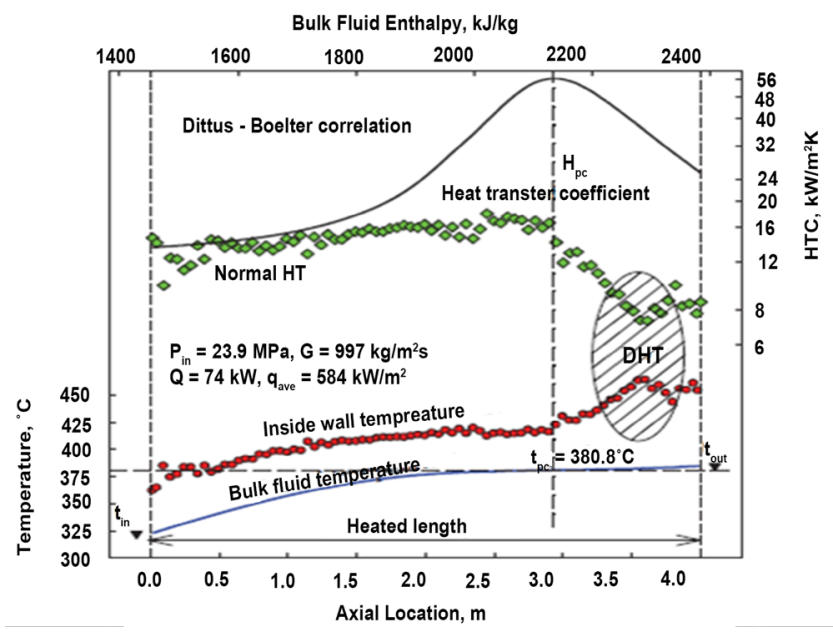

(b)

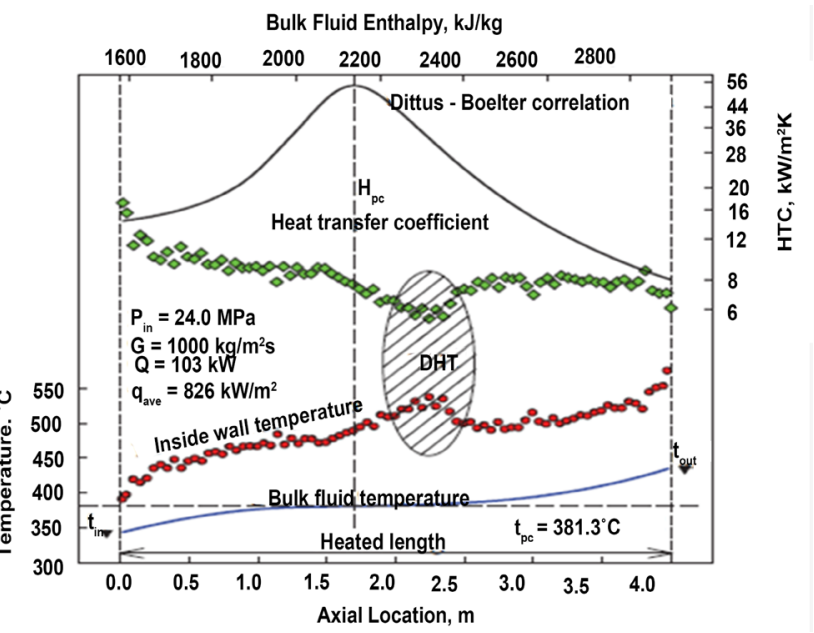

(c)

Figure 1. (a) Temperature and heat transfer coefficient profiles along heated length of vertical circular tube [7]; (b) Temperature and heat transfer coefficient profiles along heated length of vertical circular tube [7]; (c) Temperature and heat transfer coefficient profiles along heated length of vertical circular tube [7].

variation of thermophysical properties of a fluid has greater influence on heat transfer both at subcritical and at supercritical pressures. In fact, thermophysical properties of a fluid going from subcritical to supercritical state are strongly dependent on temperature, especially in the critical and pseudo-critical temperature range where thermodynamic and transport properties show rapid variations. The buoyancy effects are the result of the decrease in the density near the Pseudo-Critical Point (PCP) whereas acceleration effect results from the increase in the thermal expansion coefficient. The acceleration effect can also be explained using mass conservation principle. When a constant heat is provided to a fluid, density of the fluid decreases near the PCP and to conserve the mass, the decreased density will cause an increase in the velocity, accelerating the flow. The buoyancy effect acts always in the direction of gravitational force, irrespective of the flow direction whereas acceleration effect always acts in the direction of a flow irrespective of the gravitational force. Although these two effects are result 
of large property variation, researchers investigated these effects extensively because large changes in the density and thermal expansion coefficient affect the heat transfer phenomenon more than other properties do [11] [12]. Experiments have shown that the buoyancy effects are not limited to supercritical pressure fluids and can be seen, for example, in heat transfer to water and air at atmospheric pressure, however, in a less dramatic form due to the smaller variation in properties as compared to supercritical fluids. In order to help understand the effects of buoyancy on heat transfer, experiments and numerical studies that included both buoyancy aided flow (upward flow) and buoyancy opposed flow (downward flow) conditions were carried out (Figure 2 and Figure 3). A significant amount of work on buoyancy influenced heat transfer has been produced over the decades and is summarized by Jackson [8].

Unlike buoyancy-influenced deterioration, deterioration due to acceleration occurs only with supercritical fluids. The reason for this is the need for large variation in properties to achieve large differences in inlet and exit densities. Heat transfer deterioration HTD due to flow acceleration is present for both upward and downward flows. But, because of negligible effect of buoyancy in downward flows, it is generally believed that downward flow shows a better heat transfer behaviour than that in upward flow conditions and heat transfer enhancement is more significant in downward flow conditions compared to that of upward flows [15].

HTD is shown by graphical representation of experimental data showing broad wall temperature peaks at higher heat fluxes for horizontal flows. For a vertical upward flow, sharp temperature peaks are observed (Figure 4 and Table $1)$.

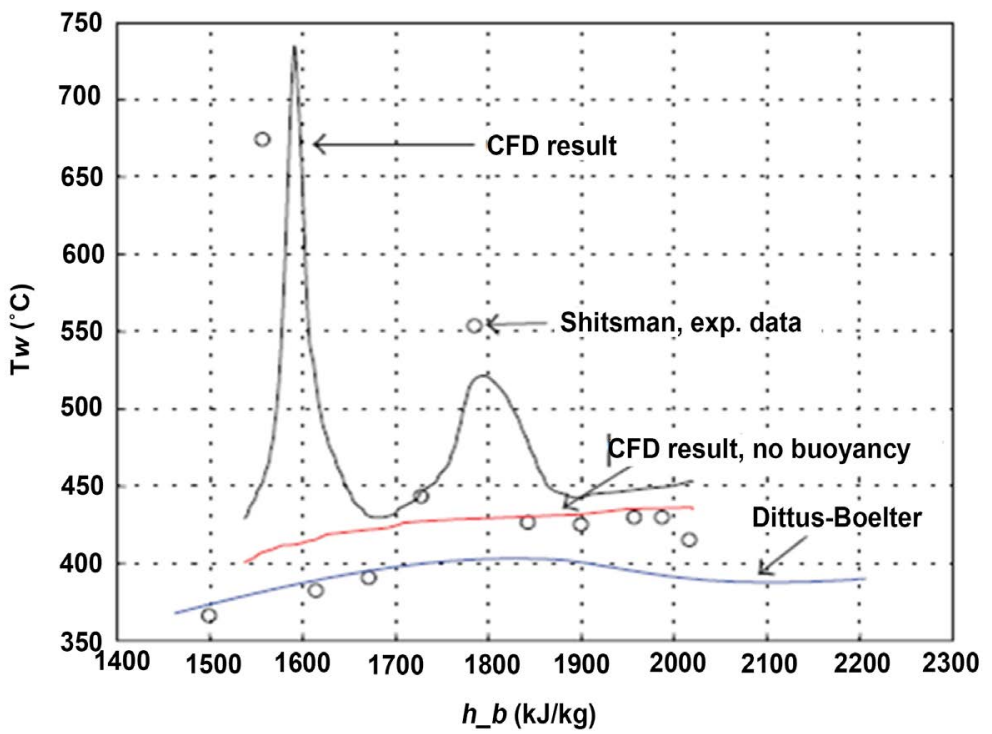

Figure 2. Comparison of the numerical results with the experiment by Shitsman and the correlation by Dittus-Boelter. Flow conditions: $p=23.3$ $\mathrm{MPa}, d=8 \mathrm{~mm}, G=430 \mathrm{~kg} / \mathrm{m}^{2} \mathrm{~s}, q=319.87 \mathrm{~kW} / \mathrm{m}^{2}$, vertical upward flow in a pipe [13] [14]. 


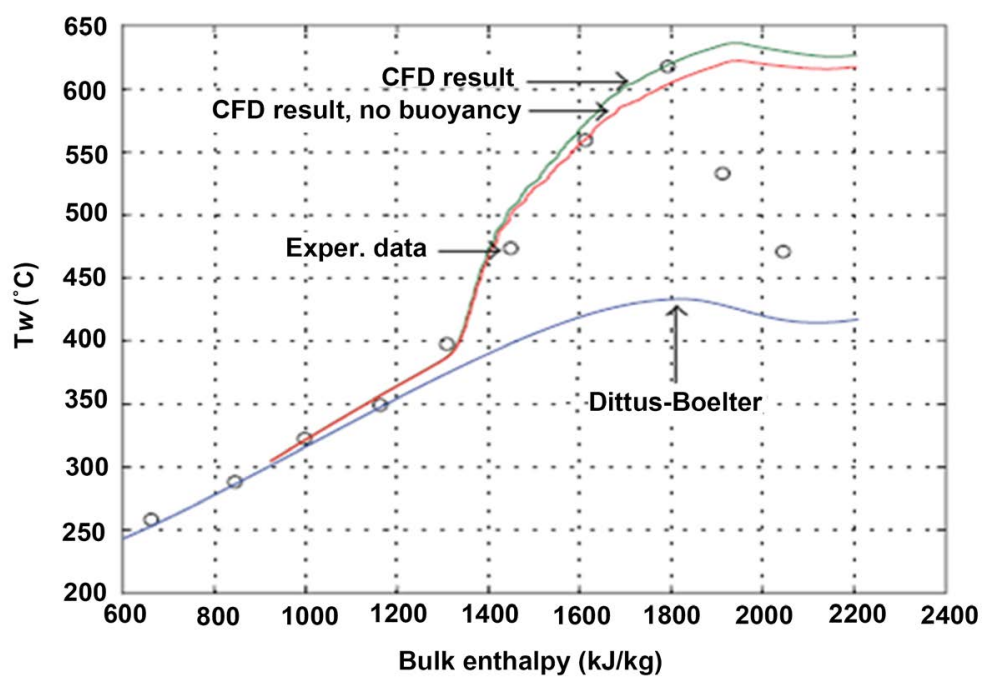

Figure 3. Comparison of the numerical results with the experiment by Ornatsky and the correlation by Dittus-Boelter. Flow conditions: $p=25.5 \mathrm{MPa}$, $d=3 \mathrm{~mm}, G=1500 \mathrm{~kg} / \mathrm{m}^{2} \mathrm{~s}, q=1810 \mathrm{~kW} / \mathrm{m}^{2}$, vertical upward flow in a pipe [13] [14].

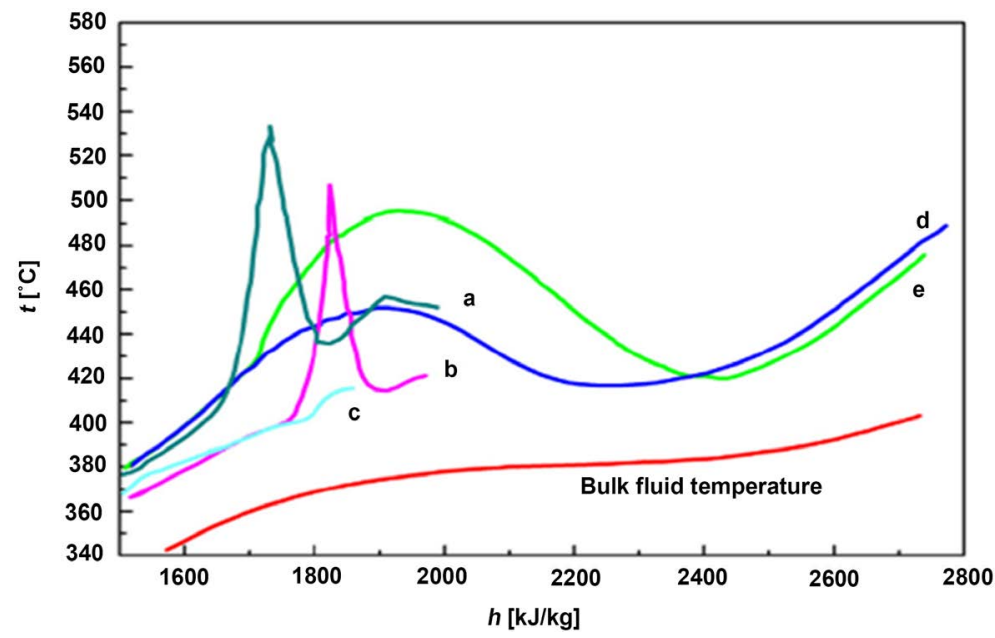

Figure 4. Experimental wall temperature distributions as a function of local bulk enthalpy along a pipe: $p=1.05 p_{\text {crit }}[16]$ [17].

Table 1. Experimental conditions for supercritical water at $p=1.05 p_{\text {crit }}[16]$.

\begin{tabular}{|c|c|c|c|c|c|}
\hline & & $q\left(\mathrm{~W} / \mathrm{cm}^{2}\right)$ & $\dot{m} / A \quad\left(\mathrm{gm} /\left(\mathrm{s} / \mathrm{cm}^{2}\right)\right)$ & $d(\mathrm{~cm})$ & Flow direction \\
\hline $\mathrm{a}$ & Shitsman & 34 & 43 & 0.8 & vertical upward \\
\hline $\mathrm{b}$ & Shitsman & 28.5 & 43 & 0.8 & vertical upward \\
\hline c & Shitsman & 28.0 & 43 & 0.8 & vertical upward \\
\hline $\mathrm{d}$ & Domin & 72.5 & 68.6 & 0.2 & horizontal \\
\hline $\mathrm{e}$ & Domin & 72.5 & 72.4 & 0.2 & horizontal \\
\hline
\end{tabular}

Jackson [10] mentioned "impaired forced convection" and "impaired mixed convection" are two different mechanisms causing heat transfer deterioration in 
fluids at supercritical pressure after retrospective consideration of some early work on heat transfer to supercritical pressure fluids.

Licht et al. [8] [9] used Figure 5 to describe NHT, IHT/EHT, DHT and recovery from HTD (heat transfer deterioration) regimes based on variation of fluid properties, mass flux and heat flux at supercritical pressures.

Zhang et al. [18] investigated heat transfer performance of $\mathrm{CO}_{2}$ in square and triangular array tube bundle using CFD code FLUENT and compared it to that of $\mathrm{H}_{2} \mathrm{O}$. It was established that the heat transfer performance of $\mathrm{CO}_{2}$ was better than that of $\mathrm{H}_{2} \mathrm{O}$. Liao and Zhao [19] reported experimental results of convection heat transfer to supercritical carbon dioxide in heated horizontal and vertical miniature tubes. Stainless steel circular tubes having diameters of $0.70,1.40$, and $2.16 \mathrm{~mm}$ were investigated. The experimental results indicated that in all the flow orientations considered, the Nusselt number decreased with reduction in tube diameter. Liu et al., 2013a numerically studied the influence of diameter on HTD in circular tubes using eight low-Reynolds-number models and compared HTD in circular tube with that in annular channel with the aim of providing detailed information on flow and turbulence structure. It was observed that an increase in tube diameter lead to the aggravation of HTD phenomena, which was more obvious at low mass flux.

\section{4) Experimental and numerical studies in heat transfer}

Experimental research to obtain data on heat transfer at supercritical pressures is important for the development of SCWR in the near future. Experimental data describe the actual behaviour of fluid flow and heat transfer, and as such are used for design and also used to validate analytical and numerical tools. Several experimental studies have been performed at supercritical conditions in trying to understand fluid flow and heat transfer at these supercritical conditions.

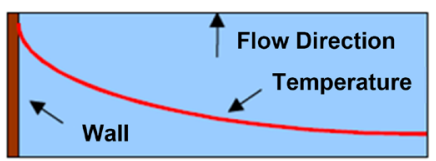

a) Normal heat transfer
(No property variation)

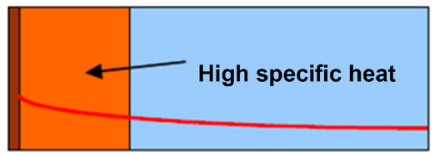

b) Enhanced heat transfer (Large G, low "Q")

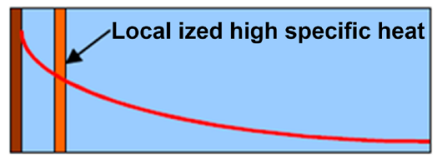

c) Impairment of enhanced heart transfer (Large G, increasing "Q")

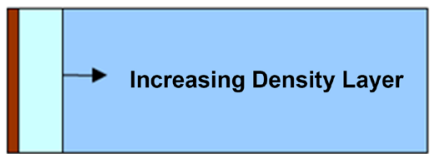

d) Deteriorating heat transfer (Low G)

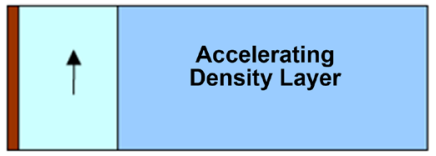

e) Recovering heat transfer (Low G)

Figure 5. Description of heat transfer regimes [8] [9]. 
Some of these experimental studies include studies carried out by Yamagata et al. [20]; Li et al. [1]; Liao and Zhao [19]; Zhang et al. [21]; Zhao et al. [15]; Wang et al. [3]; and $\mathrm{Gu}$ et al. [22] [23] [24]. Detailed descriptions of experimental studies by some of the aforementioned researchers and by others can be found in literature reviews by Cheng and Schulenberg [4], Duffey and Pioro [25], Pioro and Duffey [26], and Pioro and Duffey [5].

The recent increase in computing power and computational methods has made it possible for CFD codes to be used to reproduce experimental data and obtain data that cannot be obtained through experiments. Thus, CFD codes can be used for making predictions and providing greater detail than is offered by experiments at supercritical pressure conditions. Some of the numerical studies performed using these numerical tools include studies carried out by Zhu [27]; Liu et al. [28] [29]; Cheng et al. [30]; Jackson [10]; Sharabi [31]; Palko and Anglart [14]; Zhang et al. [18]; Wen and Gu [32]; Xi et al. [33]; Maitri [12]; and Huang et al. [34].

The major findings obtained from these experimental and numerical studies include:

1) The Normal Heat Transfer (NHT), Improved Heat Transfer (IHT) and Deteriorated Heat Transfer (DHT) are three main heat transfer regimes observed at supercritical pressures.

2) Buoyancy and bulk flow acceleration are two main mechanisms causing heat transfer deterioration at supercritical pressures as a result of significant variation of thermo-physical properties of fluids. Impaired force convection and Impaired mixed convection are two other different mechanisms reported recently to cause HTD at supercritical pressures.

3) HTD caused by flow acceleration can occur both in upward and downward flows whereas HTD caused by buoyancy can occur only in upward flows.

4) HTD caused by bulk flow acceleration can occur only at supercritical pressures whereas HTD caused by buoyancy can occur both at subcritical and supercritical pressures.

5) It was observed that a decrease in the hydraulic diameter of test geometry improves heat transfer at supercritical pressures.

6) At a high mass flux, HTD is caused by bulk flow acceleration mechanism, and at a low mass flux, HTD is caused by buoyancy mechanism.

7) Heat transfer performance of $\mathrm{CO}_{2}$ is better than that of $\mathrm{H}_{2} \mathrm{O}$ at supercritical pressures due to its significant lower critical parameters compared to that of $\mathrm{H}_{2} \mathrm{O}$.

8) Flow instability could cause HTD and might have significant effect on supercritical pressure heat transfer. Therefore more experimental and theoretical studies at supercritical pressures are needed to help further understand effects of flow instability on heat transfer.

9) There is possibility of cyclic occurrence of heat transfer deterioration HTD and restoration during flow oscillations in heated channels and HTD could occur before the occurrence of unstable behaviour at supercritical pressures. 
10) There is the need for developing and installing new turbulent models in commercial CFD codes to enable CFD codes accurately predict heat transfer at supercritical pressures. It has been established that CFD modeling could help understand heat transfer phenomenon in supercritical pressure fluid.

\section{Performance of SCW Heat Transfer Correlations}

The general purpose of heat transfer research at supercritical pressures is to provide data, heat transfer correlations and tools used for simulation, for the design of heat transfer equipment, licensing heat transfer facilities and for safe operation of these heat transfer facilities. In an attempt to achieve this purpose, several Authors made efforts to develop correlations for predicting heat transfer at supercritical pressures. Figures 6-10 were used to demonstrate the performance of some of the correlations mentioned in this section for predicting heat transfer behavior at supercritical conditions.

The Dittus-Boelter correlation which is widely used at subcritical pressures quite well predicted the experimental data in the low enthalpy region and largely over-predicted the experimental data in the high enthalpy region associated with critical and pseudo-critical conditions (Figures 7-10) [3] [15] [35].

Dittus-Boelter correlation [36] for vertical upward flow is given by Equation (1).

$$
N u_{D B, f}=0.023 \operatorname{Re}_{f}^{0.8} \operatorname{Pr}_{f}^{0.4}
$$

Equation (1) is valid for single-phase heat transfer in channels within the range of parameters (Pioro and Duffey, 2007):

$0.7 \leq \operatorname{Pr} \leq 160 ; \operatorname{Re} \geq 10,1000$ and $L / D_{h y} \geq 10$.

The Krasnoshchekov-Protopopov correlation generally predicted the experimental data quite well in the low and high enthalpy regions (Figures 7-10) except in Figure 7 where the experimental data were over-predicted in the low enthalpy region and under-predicted in the high enthalpy region [3] [15] [35]. The Krasnoshchekov-Protopopov correlation [37] [38] for vertical upward flow is given by Equation (2).

$$
N u_{b}=N u_{o}\left(\frac{\mu_{b}}{\mu_{w}}\right)^{0.11}\left(\frac{\lambda_{b}}{\lambda_{w}}\right)^{0.3}\left(\frac{\overline{C_{p}}}{C_{p b}}\right)^{0.35}
$$

$N u_{o}$ is given by Equation (3).

$$
\begin{aligned}
N u_{o} & =\frac{(\xi / 8) R e_{b} \overline{\operatorname{Pr}}}{12.7 \sqrt{(\xi / 8)}\left(\overline{\operatorname{Pr}}^{2 / 3}-1\right)+1.07} \\
\xi & =1 /\left(1.82 \log _{10} R e_{b}-1.64\right)^{2}
\end{aligned}
$$

Equation (2) is valid within the range of parameters [5]:

$$
\begin{aligned}
& 2 \times 10^{4}<R e_{b}<8.6 \times 10^{5}, 0.85<\overline{P r}_{b}<65,0.90<\mu_{b} / \mu_{w}<3.60, \\
& 1.00<k_{b} / k_{w}<6.00 \text { and } 0.07<\bar{C}_{p} / C_{p b}<4.50
\end{aligned}
$$




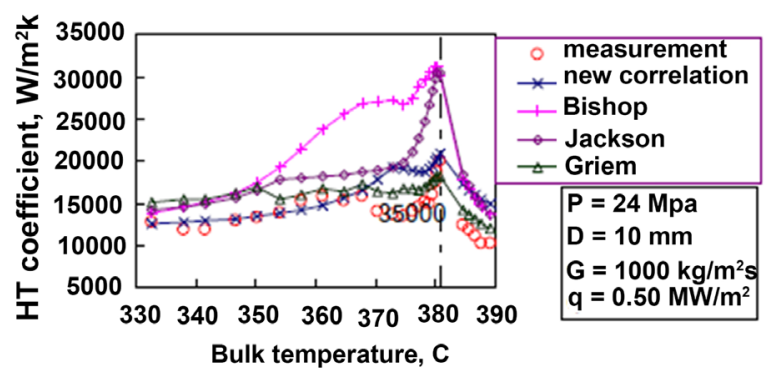

(a) at low heat flux conditions, $q=500 \mathrm{~kW} / \mathrm{m}^{2}$

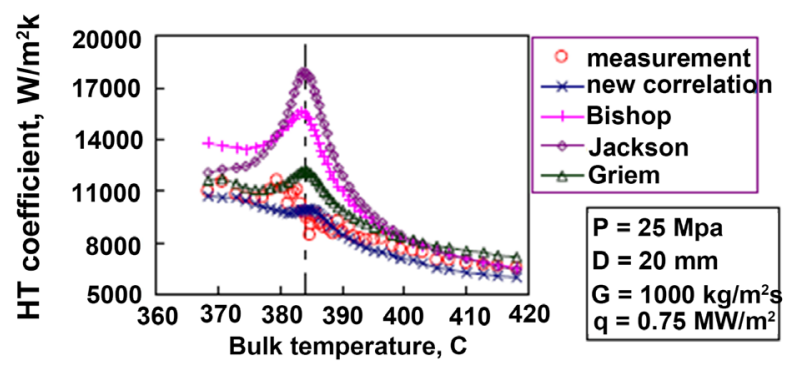

(b) at high heat flux conditions, $q=750 \mathrm{~kW} / \mathrm{m}^{2}$

Figure 6. Comparison of heat transfer correlations with experimental data at different heat flux conditions [39].

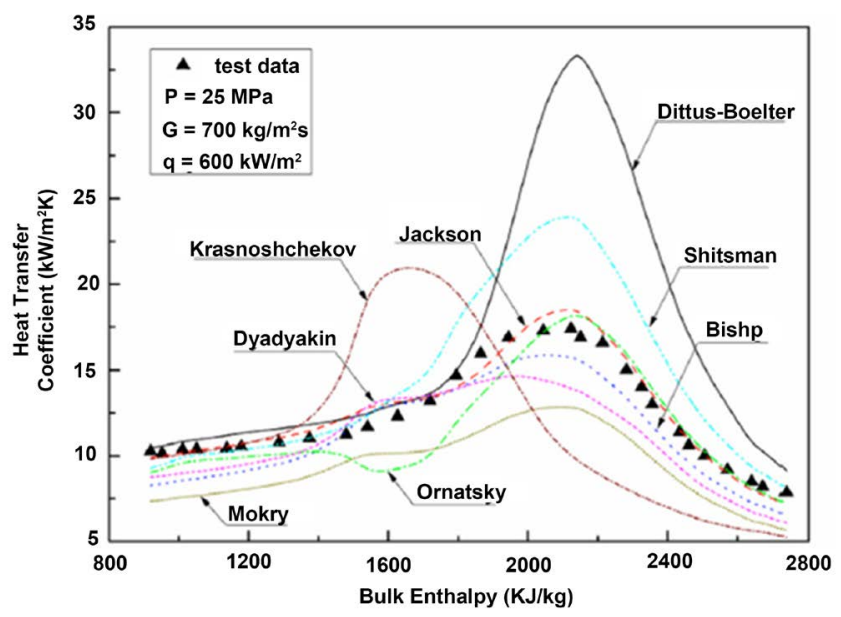

Figure 7. Comparisons of experimental and calculated heat transfer coefficient [3].

Correlation of Bishop et al. developed for annular channels predicted quite well the heat transfer coefficient experimental data for all the enthalpy range except for Figure 6 where the prediction largely deviated from the experimental data (Figure 6, Figure 7, Figure 9, Figure 10) [3] [35] [39].

Bishop et al. correlation [40] is given by Equation (5).

$$
N u_{b}=0.0069 \operatorname{Re}_{b}^{0.9} \overline{\operatorname{Pr}}_{b}^{0.66}\left(\frac{\rho_{w}}{\rho_{b}}\right)_{x}^{0.43}\left(1+2.4 \frac{D}{x}\right)
$$

where $x$ is the axial location along the heated length, $\rho_{w}$ is the density of the fluid at the wall temperature, $\rho_{b}$ is the density of the fluid at bulk temperature 


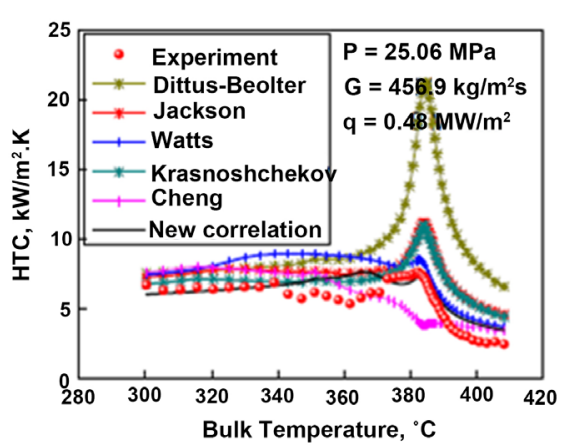

(a)

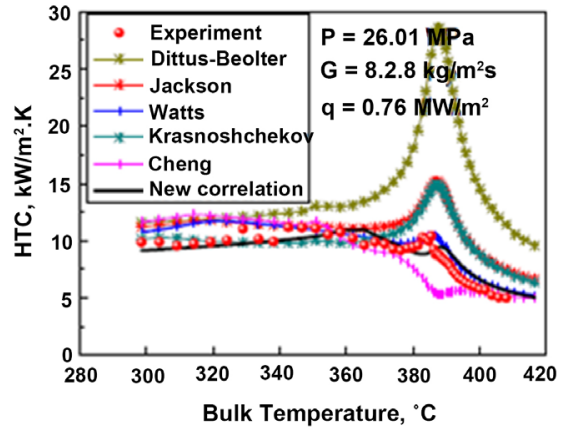

(b)

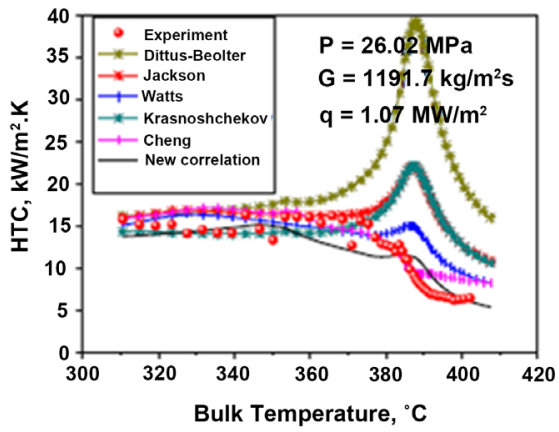

(c)

Figure 8. Examples of comparison of heat transfer correlations with test data: (a) at low heat flux condition, $q=0.48 \mathrm{MW} / \mathrm{m}^{2}$, (b) at medium heat flux condition, $q=0.76$ $\mathrm{MW} / \mathrm{m}^{2}$ and (c) at high heat flux condition, $q=1.07 \mathrm{MW} / \mathrm{m}^{2}$ [15].

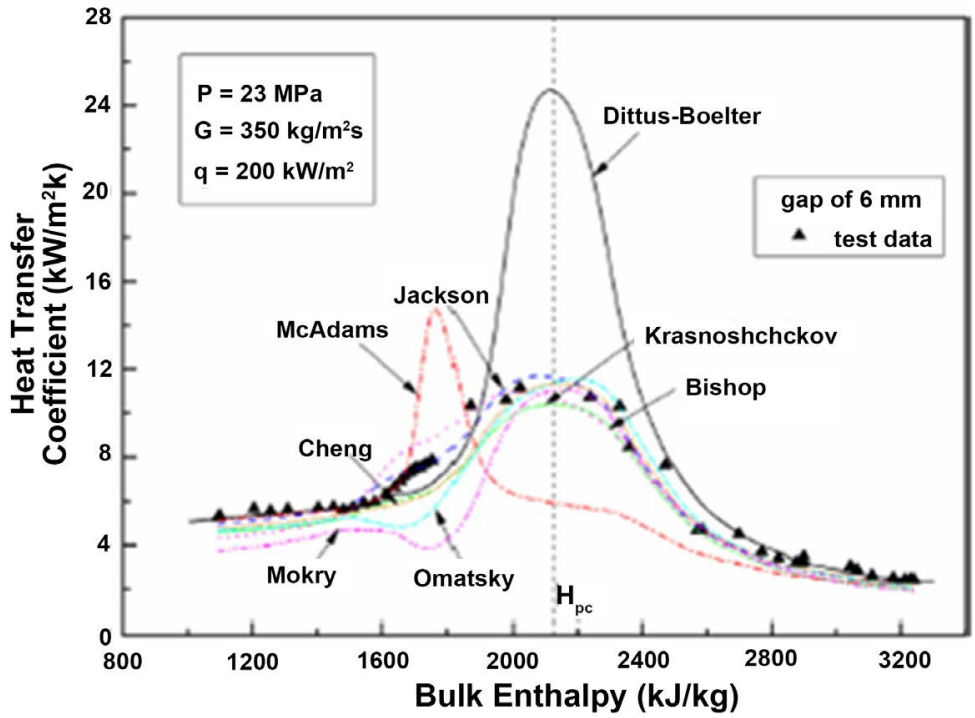

Figure 9. Comparison of experimental heat transfer coefficients with various correlations at normal heat transfer condition [35].

and the last term accounts for entrance-region effects. Equation (5) is valid within the following range of flow and operating parameters: $22.8-27.6 \mathrm{MPa}$, $282^{\circ} \mathrm{C}-527^{\circ} \mathrm{C}$ bulk-fluid temperature, $651-3662 \mathrm{~kg} / \mathrm{m}^{2} \mathrm{~s}$ mass flux and $0.31-$ $3.46 \mathrm{MW} / \mathrm{m}^{2}$ heat flux [3] [5]. 


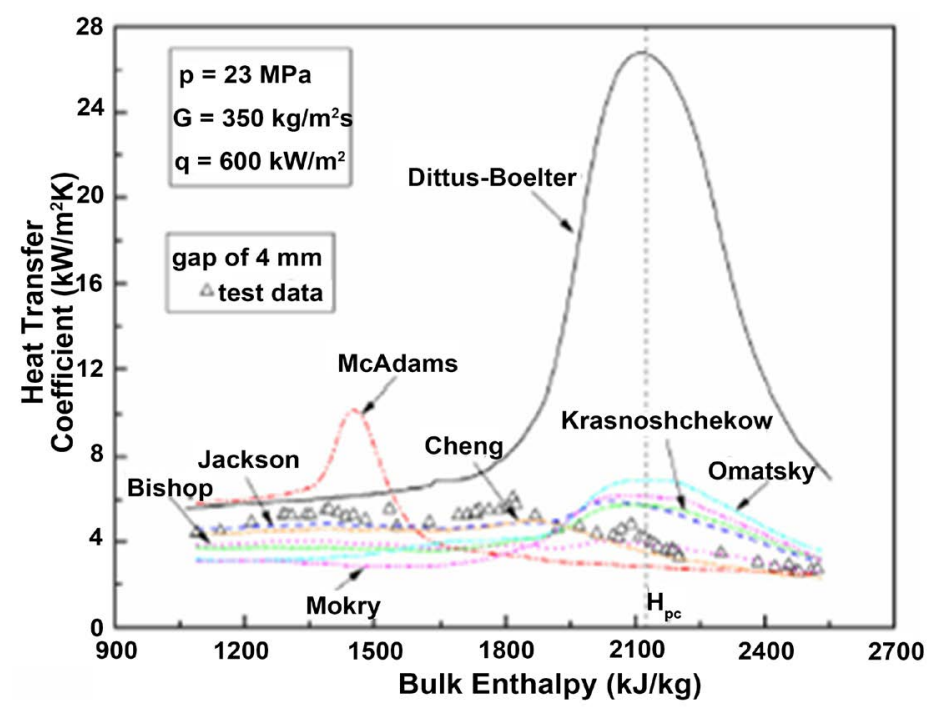

Figure 10. Comparison of experimental heat transfer coefficients with various correlations at deteriorated heat transfer condition [35].

Correlation of Dyadyakin and Popov developed for fuel bundles predicted closely experimental heat-transfer coefficients over a narrow range of bulk-fluid enthalpy (Figure 7). The experimental data of heat transfer coefficients were slightly under-predicted beyond that range [3].

Dyadyakin and Popov correlation [41] for supercritical water heat transfer for fuel bundles is given by Equation (6).

$$
N u_{x}=0.0021 \operatorname{Re}_{x}^{0.8} \overline{\operatorname{Pr}_{x}^{0.7}}\left(\frac{\rho_{w}}{\rho_{b}}\right)_{x}^{0.45}\left(\frac{\mu_{b}}{\mu_{i n}}\right)_{x}^{0.2}\left(\frac{\rho_{b}}{\rho_{\text {in }}}\right)_{x}^{0.1}\left(1+2.5 \frac{D_{h y}}{x}\right)
$$

where $x$ is the axial location along the heated length and $D_{h y}$ is the hydraulic diameter. Equation (6) is valid within the range of the parameters: $24.5 \mathrm{MPa}$, $90^{\circ} \mathrm{C}-570^{\circ} \mathrm{C}$ bulk temperature ( $400-3400 \mathrm{~kJ} / \mathrm{kg}$ bulk enthalpy), $<4.7 \mathrm{MW} / \mathrm{m}^{2}$ heat flux and $500-4000 \mathrm{~kg} / \mathrm{m}^{2}$ s mass flux [5].

Ornatsky et al. correlation [42] closely predicted the trend of the experimental heat transfer coefficient values (Figure 7, Figure 9). The correlation under-predicted the experimental data in the low enthalpy region and over-predicted the experimental data in the high enthalpy region (Figure 10). The Ornatsky et al. correlation is given by Equation (7) [3].

$$
N u_{b}=0.023 \operatorname{Re}_{b}^{0.8} \operatorname{Pr}_{b}^{0.8}\left(\frac{\rho_{w}}{\rho_{b}}\right)^{0.3}
$$

Equation (7) is valid within the range of parameters: 22.6 - 29.4 MPa, 420 $1400 \mathrm{~kJ} / \mathrm{kg}$ inlet enthalpy, $0.28-1.2 \mathrm{MW} / \mathrm{m}^{2}$ heat flux and $450-3000 \mathrm{~kg} / \mathrm{m}^{2} \mathrm{~s}$ mass flux [5].

The Shitsman correlation mostly over-predicted experimental values at high Nusselt numbers as shown in Figure 7 [3]. The Shitsman correlation [43] is given by Equation (8). 


$$
N u_{b}=0.023 \operatorname{Re}_{b}^{0.8} \operatorname{Pr}_{\min }^{0.8}
$$

Equation (8) is valid within the range of parameters: $22.6-27.4 \mathrm{MPa}, 180^{\circ} \mathrm{C}$ $580^{\circ} \mathrm{C}$ bulk temperature, $0.28-8.4 \mathrm{MW} / \mathrm{m}^{2}$ heat flux and $170-3000 \mathrm{~kg} / \mathrm{m}^{2} \mathrm{~s}$ mass flux [5].

Griem correlation slightly deviated in predicting the experimental data at low and high heat flux conditions shown in Figure 6. Griem correlation [44] for forced convection heat transfer at critical and supercritical pressures in tubes is given by Equation (9).

$$
N u_{b}=0.0169 \operatorname{Re}_{b}^{0.8356} \operatorname{Pr}_{b}^{0.432}
$$

Equation (9) is valid within the range of parameters: $23-25 \mathrm{MPa}, 0.3-0.6$ $\mathrm{MW} / \mathrm{m}^{2}$ heat flux, and $500-2500 \mathrm{~kg} / \mathrm{m}^{2}$ s mass flux [39].

The correlation of Mokry et al. under-predicted experimental heat-transfer coefficient over entire range of bulk-fluid enthalpy as shown in Figure 7 [3]. The Mokry et al. correlation [45] is given by Equation (10).

$$
N u_{b}=0.0061 \operatorname{Re}_{b}^{0.904} \overline{\operatorname{Pr}}_{b}^{0.684}\left(\frac{\rho_{w}}{\rho_{b}}\right)_{x}^{0.564}
$$

Equation (10) is valid within the range of parameters: $24 \mathrm{MPa}, 320^{\circ} \mathrm{C}-350^{\circ} \mathrm{C}$ inlet temperature, $\leq 1250 \mathrm{~kW} / \mathrm{m}^{2}$ heat flux and $200-1500 \mathrm{~kg} / \mathrm{m}^{2}$ s mass flux [45].

The Jackson correlation [46] predicted closely experimental heat-transfer coefficients over entire range of bulk-fluid enthalpy at supercritical fluid flow conditions. It captured trend of experimental values at both low and high enthalpy regions (including the pseudo-critical point) (Figure 6, Figure 7, Figure 9, Figure 10) except in Figure 6 where the experimental data of heat transfer coefficient values were poorly predicted by the correlation in most of the enthalpy region. The Jackson correlation, which is the modified form of the correlation of Krasnoshchekov et al. for upward vertical flow is given by Equation (11) [46].

$$
\begin{gathered}
N u_{b}=0.0183 \operatorname{Re}_{b}^{0.82} \operatorname{Pr}_{b}^{0.5}\left(\frac{\rho_{w}}{\rho_{b}}\right)^{0.3}\left(\frac{\overline{C_{p}}}{C_{p b}}\right)^{n} \\
n=0.4 \text { for } T_{b}<T_{w}<T_{p c} \text { and for } 1.2 T_{p c}<T_{b}<T_{w} \\
n=0.4+0.2\left(\frac{T_{w}}{T_{p c}}-1\right) \text { for } T_{b}<T_{p c}<T_{w} \\
n=0.4+0.2\left(\frac{T_{w}}{T_{p c}}-1\right)\left[1-5 \frac{T_{b}}{T_{p c}}-1\right] \text { for } T_{p c}<T_{b}<1.2 T_{p c}
\end{gathered}
$$

where $T_{b}, T_{p c}$ and $T_{w}$ are in K. Hence it can be expected that the Jackson correlation will follow closely a trend predicted by the Krasnoschekov et al. correlation. Equation (11) is valid within the range of parameters [5]:

$$
\begin{aligned}
& 8 \times 10^{4}<\operatorname{Re}_{b}<5.10^{5}, 0.85<\overline{P r}_{b}<65,0.90<\rho_{w} / \rho_{b}<1.0,0.9<T_{w} / T_{p c}<2.5, \\
& 4.6 \times 10^{4}<q<2.6 \times 10^{6}\left(q \text { in } \mathrm{W} / \mathrm{m}^{2}\right), 0.02<\bar{C}_{p} / C_{p b}<4.0 \text { and } x / D \geq 15
\end{aligned}
$$


Cheng et al. [39] proposed a new simplified heat transfer correlation for vertical fluid flow based on phenomenological assessment of heat transfer behaviour, and compared the correlation with existing test data of Herkenrath et al. and correlations of Bishop et al., Griem et al. and Jackson (Figure 6). The new correlation of Cheng et al. performed well in predicting the experimental heat transfer coefficient values in the whole enthalpy range and over a wide parameter range when compared with other correlations (Figure 6). Cheng et al. mentioned that the newly developed correlation could perform well in predicting heat transfer behavior in the heat transfer deterioration region. The new correlation of Cheng et al. [39] for vertical fluid flow is given by Equation (15).

$$
\begin{gathered}
N u=0.023 \operatorname{Re}_{B}^{0.8} \operatorname{Pr}^{1 / 3} \cdot F \\
F=\min \left(F_{1}, F_{2}\right) \\
F_{1}=0.85+0.776\left(\pi_{A} \cdot 10^{3}\right)^{2.4} \\
F_{2}=\frac{0.48}{\left(\pi_{A, P C} \cdot 10^{3}\right)^{1.55}}+1.21 \cdot\left|\left(1-\frac{\pi_{A}}{\pi_{A, P C}}\right)\right|
\end{gathered}
$$

where $\pi_{A}$ is the acceleration parameter given by

$$
\pi_{A}=\frac{q \cdot \beta_{B}}{G \cdot C_{p . B}}
$$

Equation (15) is valid within the range of parameters (test data for Herkenrath et al. [47]: $22.5-25.0 \mathrm{MPa}, 300^{\circ} \mathrm{C}-450^{\circ} \mathrm{C}$ bulk temperature, $0.30-2.0 \mathrm{MW} / \mathrm{m}^{2}$ heat flux and $700-3500 \mathrm{~kg} / \mathrm{m}^{2} \mathrm{~s}$ mass flux [5] [39].

Wang et al. [3] performed experiments on heat transfer with water at supercritical pressure flowing vertically upward through a $2 \times 2 \operatorname{rod}$ bundle. Using the experimental data, they developed a new correlation for the rod bundle which predicted the experimental data quite better when compared with other correlations. Wang et al. actually compared their experimental results with predicted results of eight correlations indicated in Figure 7. It was observed that correlations of Dittus-Boelter, Shitsman, Krasnoshchekov et al., Mokry et al. and Ornatsky et al. largely deviated from the experimental data at certain operating conditions including HDT conditions. Correlations of Dyadyakin and Popov, and Bishop et al. quite well predicted the experimental trend. Correlation of Jackson best and closely predicted the experimental trend in both the low and high Nusselt-number regions. Wang et al. therefore, re-optimized the coefficients and exponents of the Jackson correlation using their current set of experimental parameters and heat-transfer coefficients. Wang et al. correlation [3] which was obtained as a result of the optimization of correlation for Jackson Nusselt number is given by Equation (20).

$$
N u_{b}=0.01 \operatorname{Re}_{b}^{0.88} \operatorname{Pr}_{b}^{0.64}\left(\frac{\rho_{m}}{\rho_{b}}\right)^{1.76}\left(\frac{\overline{C_{p}}}{C_{p b}}\right)^{0.49}
$$

The qualitative temperature for density is the film temperature but not the 
wall temperature in the correlation of Jackson. Equation (20) is valid within the range of parameters: $23-28 \mathrm{MPa},<500^{\circ} \mathrm{C}$ bulk temperature, $200-1000 \mathrm{~kW} / \mathrm{m}^{2}$ heat flux and $700-3500 \mathrm{~kg} / \mathrm{m}^{2}$ s mass flux [3].

The Watt and Chou correlation performed quite well in predicting heat transfer for downward vertical flow as shown in Figure 8 [15]. The Watt and Chou correlation [48] for predicting heat transfer to fluid flowing vertically downward is given by Equation (21).

$$
\begin{aligned}
& N u=N u_{v a r P}\left[1-\frac{3000 \overline{G r_{b}}}{R e_{b}^{2.7} \cdot{\overline{P r_{b}}}^{0.5}}\right]^{0.295} \text { for } \frac{\overline{G r_{b}}}{\operatorname{Re}_{b}^{2.7} \cdot \overline{\operatorname{Pr}}_{b}^{0.5}}<10^{-4} \\
& N u=N u_{v a r P}\left[\frac{7000 \overline{G r_{b}}}{R e_{b}^{2.7} \cdot \overline{P r}_{b}^{0.5}}\right]^{0.295} \text { for } \frac{\overline{G r_{b}}}{R e_{b}^{2.7} \cdot \overline{P r}_{b}^{0.5}}>10^{-4}
\end{aligned}
$$

where

$$
\begin{gathered}
N u_{\text {varP }}=0.021 \operatorname{Re}_{b}^{0.8} \cdot \overline{\operatorname{Pr}_{b}}{ }^{0.55}\left(\frac{\rho_{w}}{\rho_{b}}\right)^{0.35} \\
\overline{G r_{b}}=\frac{g \cdot \rho_{b} \cdot d^{3} \cdot\left(\rho_{b}-\bar{\rho}\right)}{\mu_{b}^{2}} \\
\overline{\operatorname{Pr}_{b}}=\frac{\overline{C_{p}} \cdot \mu_{b}}{\lambda_{b}} \\
\overline{C_{p}}=\frac{h_{w}-h_{b}}{T_{w}-T_{b}} \\
\bar{\rho}=\frac{\rho_{w}+\rho_{b}}{2}
\end{gathered}
$$

Equation (21) is valid within the range of parameters: $25 \mathrm{MPa}, 150^{\circ} \mathrm{C}-310^{\circ} \mathrm{C}$ bulk temperature, $0.175-0.44 \mathrm{MW} / \mathrm{m}^{2}$ heat flux and $106-1060 \mathrm{~kg} / \mathrm{m}^{2} \mathrm{~s}$ mass flux [5] [39].

Jackson [49] proposed another correlation for predicting heat transfer in downward vertical flow at supercritical pressures. The Jackson correlation [49] is given by Equation (28) and valid within a wide range of flow conditions at supercritical pressures.

$$
\frac{N u_{b}}{N u_{f}}=\left[\left|1 \pm 1875 B o_{b} F_{V 1}\left(\frac{N u_{b}}{N u_{f}}\right)^{-1.1}\right|\right]^{0.46}
$$

where

$$
\begin{gathered}
N u_{f}=0.023 \operatorname{Re}_{b}^{0.8} \operatorname{Pr}_{b}^{1 / 3} \\
B o_{b}=\frac{G r_{b}}{\operatorname{Re}_{b}^{2.625} \operatorname{Pr}_{b}^{1 / 3}} \\
F_{V 1}=\left(\frac{\bar{\mu}}{\mu_{b}}\right)\left(\frac{\bar{\rho}}{\rho_{b}}\right)^{-0.5}
\end{gathered}
$$


Recently, Jackson introduced new Buoyancy parameter to further improve upon his prediction method for heat transfer of supercritical fluids [15]. The new Buoyancy parameter for downward vertical flow is given by Equation (32). Jackson's correlation for downward vertical flow performed well in predicting the experimental data in the low enthalpy region and largely over-predicted the experimental data in the high enthalpy region (Figure 8). The experimental values were over-predicted over the whole enthalpy range by the correlation.

$$
B o=\frac{G r_{B}}{R e_{B}^{3.425} \operatorname{Pr}_{B}^{0.8}}
$$

where

$$
G r_{B}=\frac{g \cdot \rho_{B} \cdot d^{3} \cdot\left(\rho_{B}-\rho_{w}\right)}{\mu_{B}^{2}}
$$

Zhao et al. [15] performed experiments to study heat transfer to supercritical water flowing downward in circular tubes. They proposed new correlation for downward flow given by Equation (34).

$$
\begin{gathered}
N u=0.023 \operatorname{Re}_{b}^{0.8} \operatorname{Pr}^{1 / 3} \cdot F \\
F=\min \left(F_{1}, F_{2}\right) \\
F=F_{1}=0.62+0.06 \times \ln \left(\pi_{B}\right) \\
F=F_{2}=11.46 \times\left(\ln \pi_{B}\right)
\end{gathered}
$$

where $\pi_{B}$ is the Buoyancy parameter given by Equation (38).

$$
\pi_{B}=\frac{q \cdot \beta_{B} \cdot d}{\lambda_{B}}
$$

Zhao et al. compared the performance of their newly developed correlation with their experimental data and heat transfer correlations of Watts and Chou, Jackson, Dittus-Boelter, Krasnoschkov et al., and Cheng (b). The correlation of Zhao et al. performed quite well in predicting the experimental data compared to the other correlations. Equation (34) is valid within the range of parameters: 23 - $26 \mathrm{MPa}, 280^{\circ} \mathrm{C}-410^{\circ} \mathrm{C}$ bulk temperature, $0.17-1.4 \mathrm{MW} / \mathrm{m}^{2}$ heat flux and $450-1500 \mathrm{~kg} / \mathrm{m}^{2} \mathrm{~s}$ mass flux [15].

McAdams et al. correlation [50] which mostly over-predicted the experimental data in the low enthalpy region and under-predicted experimental data in the high enthalpy region (Figure 9, Figure 10) is given by Equation (39) [35].

$$
N u_{b}=0.0214 R e_{f}^{0.8} P r_{f}^{0.33}\left(1+2.3 d_{h y} / l\right)
$$

Equation (39) is valid within the range of parameters: $0.8-24 \mathrm{MPa}, 221^{\circ} \mathrm{C}$ $538^{\circ} \mathrm{C}$ bulk temperature, $0.035-0.336 \mathrm{MW} / \mathrm{m}^{2}$ heat flux and $75-224 \mathrm{~kg} / \mathrm{m}^{2} \mathrm{~s}$ mass flux [5].

Gang et al. [35] performed experiments on heat transfer of supercritical water flowing in vertical annular channels (gaps of $4 \mathrm{~mm}$ and $6 \mathrm{~mm}$ ) at normal and deteriorated heat transfer conditions and evaluated the performance of eight heat transfer correlations against their experimental results. The eight correla- 
tions include five correlations of Dittus and Boelter, Jackson, Mokry et al., Krasnoshchekov-Protopopov, and Cheng et al. developed for tube geometry, and three other correlations of McAdams et al., Bishop et al. and Ornatsky et al. developed for annular flow channel (Figure 9 and Figure 10).

For normal heat transfer condition as shown in Figure 9, all of the eight correlations predicted quite well the experimental data in low and high enthalpy regions. Correlations of Jackson and Cheng best predicted the experimental data in the pseudo-critical enthalpy region. The correlations of Bishop and Krasnoshchekov slightly under-predicted the experimental data near the pseudo-critical enthalpy region. Dittus-Boelter correlation over-predicted the experimental data on heat transfer coefficient while the Mcadams correlation showed an early peak of heat transfer coefficient. Both Mokry and Orantsky correlations both produced a valley of heat transfer coefficient values near the enthalpy of $1700 \mathrm{~kJ} / \mathrm{kg}$, an observation which was different from that of the experimental trend.

For heat transfer deterioration condition as shown in Figure 10, the correlations predicted different trends in the low enthalpy and pseudo-critical enthalpy regions. In low enthalpy region, Jackson and Cheng correlations best predicted the experimental data while Bishop, Mokry, Krasnoshchekov, and Ornatsky correlations under-predicted the experimental data in this region. In the pseudo-critical enthalpy regions, the correlations of Bishop and Cheng well predicted the experimental trend of heat transfer coefficient values while correlations of Jackson, Krasnoshchekov, Mokry and Ornasky showed slight deviations from the experimental trend. As usual, Dittus-Boelter correlation largely over-predicted the experimental trend in the pseudo-critical enthalpy region. It can be observed that only the Cheng correlation that predicted the experimental trend within the acceptable limit over the whole enthalpy range for HTD [35].

Similar studies have been carried out using different assessment methods including statistical method to evaluate heat transfer correlations at supercritical pressures. Results of these studies are presented in the IAEA-TECDOC-1746 (2014) and in papers written by Zahlan et al. [51] [52].

\section{Correlations for Determining the Onset of Heat Transfer Deterioration}

Heat transfer deterioration HTD phenomenon is an issue as far as fluid flow and heat transfer processes are concerned and there is the need to determine the onset of HTD. Determining the onset of HTD is therefore important for the design and operation of heat transfer equipment at supercritical pressures. Table 2 shows some selected heat transfer correlations used for determining the onset of HTD at supercritical pressures. Schatte et al. [53] compared six (6) of these correlations including Vikhrev et al. [54]; Styrikovich et al. [55]; Yamagata et al. [20]; Mokry et al. [45]; Cheng et al. [39]; and Li et al. [56] with their newly developed correlation (Table 2 and Figure 11). The bar line in the Figure 11 indicates all the data points that are within $\pm 15 \%$ of the experimental data. Most of 
Table 2. Existing correlations for predicting onset of HTD with $\dot{q}_{D H T}$ in $\mathrm{kW} / \mathrm{m}^{2}, p$ in bar, $d_{i}$ in $\mathrm{mm}, \mathrm{kg} / \mathrm{m}^{2} \mathrm{~s}, C_{p}$ in $\mathrm{kJ} / \mathrm{kg} \mathrm{K}$, and $\beta$ in $1 / \mathrm{K}$.

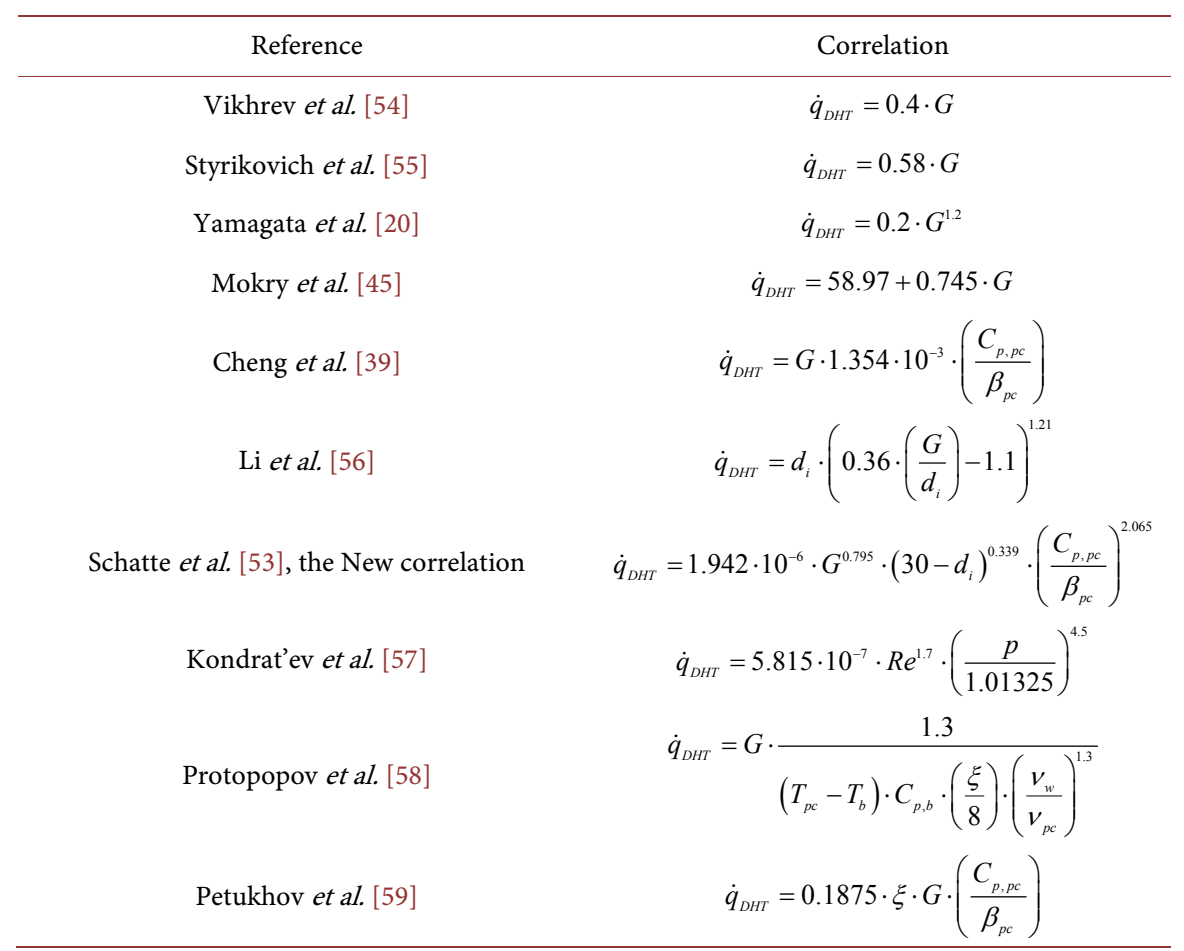

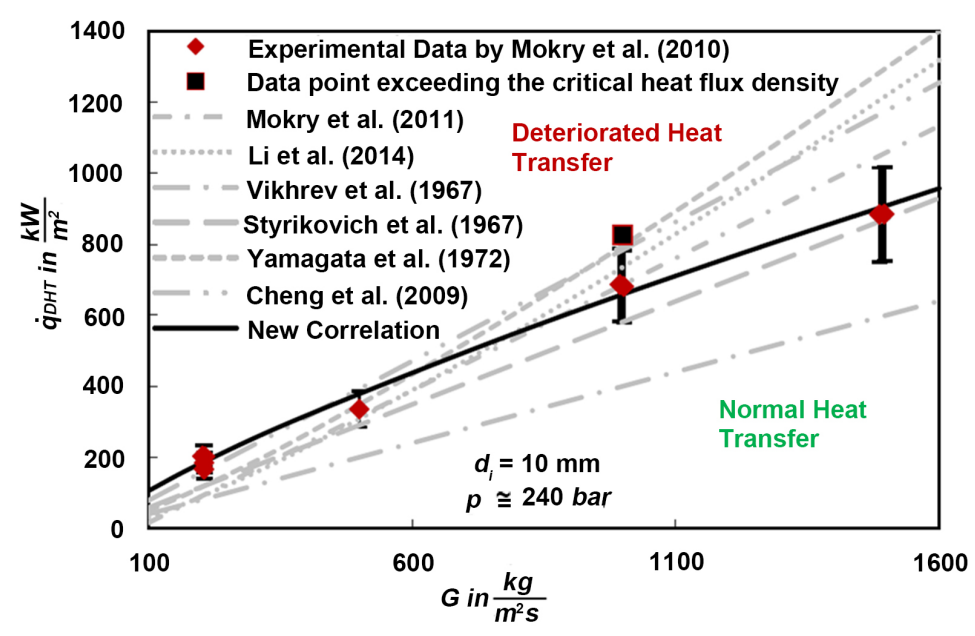

Figure 11. Plot of the heat flux causing the onset of DHT predicted by the existing correlations and the new correlation compared against experimental points by Mokry et al. [7]. Bars indicate the $\pm 15 \%$ range.

the correlations under-predicted the experimental at low mass fluxes and over-predicted the experimental data at high mass fluxes. Correlations of Styrikovich et al. [55] and Vikhrev et al. [54] under-predicted all the experimental data. The new correlation of Schatte et al. [53] best predicted the experimental data by Mokry et al. [7] with all the data points within the $\pm 15 \%$ of the experimental data. Correlations of Styrikovich et al. [55] and Mokry et al. [45] quite well predicted the experimental data followed by the correlations of Li et al. [56] 
and Cheng et al. [39]. Correlations of Yamagata et al. [20] and Vikhrev et al. [54] poorly predicted the experimental data. More details on the onset of heat transfer correlations can be found in Schatte et al. [53] and the mentioned references for the various correlations.

In fluid flow and heat transfer systems where the fluid flow is affected by buoyancy, the existing heat transfer correlations are unable to capture heat transfer characteristics including the onset of HTD. Researchers have therefore made effort to develop criterion to predict the occurrence of buoyancy in fluid flow and heat transfer systems.

The onset of HTD due to buoyancy could be determined using the criterion of Jackson and Hall, or the criterion of Seo et al. [9]. Jackson and Hall criterion (Equation (40)) was derived from simple boundary layer theory and the criterion of Seo et al. (Equation (41)) was developed based on the Froude number, which can be defined as the ratio of inertial forces to buoyant forces.

The most accurate Jackson and Hall buoyancy criterion is given by Equation (40).

$$
\frac{\overline{G r}_{b}}{R e_{b}^{2.7}}<10^{-5}
$$

Jackson and Hall criterion limiting value of less than $10^{-5}$ is needed for negligible buoyancy effects.

The recent buoyancy criterion of Seo et al. is given by Equation (41).

$$
\frac{1}{F r} \approx \frac{1}{\rho_{b}} \frac{\rho_{b}-\rho_{s}}{T_{s}-T_{b}} \frac{Q^{\prime \prime} D_{H}}{k_{s}} \frac{g D_{H}^{3}}{v_{s}^{2}} \frac{1}{R e_{s}^{2.8} N u}<0.3
$$

In Equation (41), the $s$ subscript denotes properties similar to a film temperature and is defined as an average of the inlet and pseudo-critical temperature. The Nusselt number $\mathrm{Nu}$ is based on the Dittus-Boelter Nusselt correlation, and an inverse Froude number of less than 0.3 is needed for negligible buoyancy effects.

\section{SCW Pressure Drop Relations}

The various relations used for estimating the total pressure drop or the total hydraulic resistance are in terms of Design variables and Control variables or Operating parameters. The value of the total pressure drop associated with the designed system is used to check whether the Design and Control Variables are within the safety limits of operation. Small pressure drop indicates good design and the range of control variables associated with small pressure drop are within the safety limit of operation. Large pressure drop indicates poor system design and the associated design and control variables are not within the safety limit of operation.

The total pressure drop for forced convection flow inside a closed-loop system can be determined using the expression [5]:

$$
\Delta P=\Sigma \Delta P_{f r}+\Sigma \Delta P_{l}+\Sigma \Delta P_{a c}+\Sigma \Delta P_{g}
$$


where $\Delta P_{f r}, \Delta P_{l}, \Delta P_{a c}$ and $\Delta P_{g}$ are the pressure drop due to frictional resistance, local flow obstruction, acceleration of flow, and gravity respectively.

The pressure drop due to frictional resistance can be calculated using

$$
\Delta P_{f r}=\xi_{f r} \frac{L \rho u^{2}}{2 D}=\xi_{f r} \frac{L G^{2}}{2 D \rho}
$$

where $\xi_{f r}$ is the frictional resistance coefficient or simply called friction factor. The friction factor $\xi_{f r}$ is not to be confused with the friction coefficient, sometimes called the Fanning friction factor. Denoting the Fanning friction factor by $f$, it follows that

$$
\xi_{f r}=4 f
$$

The thermophysical properties in the equations should be evaluated based on the arithmetic average of inlet and outlet values.

Mikheev correlation for frictional resistance coefficient $\xi_{f r}$ of non-isothermal flow of water and other fluids is given by Equation (45).

$$
\xi_{f r}=\frac{1}{\left(1.82 \log _{10} R e_{b}-1.64\right)^{2}}\left(\frac{P r_{w}}{P r_{b}}\right)^{\frac{1}{3}}
$$

The Equation is valid for smooth tubes within a range of $R e>4000$ (turbulent stabilized flow) [5].

Equation (46) was recommended for calculating frictional resistance coefficient $\xi_{f r}$ for turbulent flows at supercritical pressures [4].

$$
\xi_{f r}=f_{o}\left(\frac{\rho_{w}}{\rho_{B}}\right)^{0.4}
$$

With

$$
f_{o}=(1.82 \log (\operatorname{Re} / 8))^{-2.0}
$$

The Colebrook equation can be used to estimate friction factor $\xi_{r}$ at supercritical pressures. The equation was derived by combining experimental results of laminar and turbulent flow in pipes. An approximate explicit form of the Colebrook equation was given by Haaland [60], which is Equation (48). The surface roughness $\mathcal{E}$ can be set to $1.5 \times 10^{-6} \mathrm{~m}[61]$.

$$
\xi_{r}=\left[-1.8 \log \left(\left(\frac{\varepsilon}{3.7 D}\right)^{1.11}+\frac{6.9}{R e}\right)\right]^{-2}
$$

The friction factor $\xi_{r}$ can also be determined using the Blasius and McAdams relations for smooth pipe at supercritical pressures (Equation (49)) [62].

$$
\xi_{r}=\left\{\begin{array}{lc}
\frac{64}{R e} & R e \leq 2200 \\
\max \left(\frac{64}{R e}, \frac{0.316}{R e^{0.25}}\right) & 2200<R e<3000 \\
\frac{0.316}{R e^{0.25}} & R e \geq 3000
\end{array}\right.
$$


The Blasius friction factor equation (Equation (50)) which is based on the assumption of fully developed turbulent flow in a smooth tube can also be used to estimate friction factor $\xi_{r}$ at supercritical pressures. It is applicable for bulk Reynolds numbers $\left(R e_{b}\right)$ up to $10^{5}$ [63].

$$
\xi_{r}=\frac{0.316}{\operatorname{Re}_{b}^{1 / 4}}
$$

The implicit and iterative Colebrook and White (C-W) equation (Equation (51)) is also used to obtain friction factor at supercritical conditions [63].

$$
\frac{I}{f_{C-W}^{1 / 2}}=-2 \log \left(\frac{\varepsilon / D}{3.7}+\frac{2.5 I}{R e_{b} \sqrt{f_{C-W}}}\right)
$$

The frictional resistance coefficient changes at supercritical pressures due to significant property changes near the critical and pseudocritical points. Other correlations for calculating friction factor or frictional resistance coefficient can be found in Pioro and Duffey [5].

The pressure drop due to local flow obstructions is defined as:

$$
\Delta P_{l}=\xi_{l} \frac{G^{2}}{2 D}
$$

where the local resistance coefficient, $\xi_{l}$, is determined using appropriate correlations for different flow obstructions. Significant property changes at supercritical flow conditions also affect the local resistance coefficients.

The pressure drop due to acceleration of flow is defined as:

$$
\Delta P_{a c}=G^{2}\left(\frac{1}{\rho_{\text {out }}}-\frac{1}{\rho_{\text {in }}}\right)
$$

The pressure due to gravity is defined as:

$$
\Delta P_{g}= \pm g\left(\frac{H_{\text {out }} \rho_{\text {out }}+H_{\text {in }} \rho_{\text {in }}}{H_{\text {out }}+\rho_{\text {in }}}\right) L \sin \theta
$$

where $\theta$ is the test-section inclination angle to the horizontal plane, the sign "+" is for the upward flow, and the sign "-" is for the downward flow. Equation (42) is applicable for subcritical and supercritical pressures [5].

\section{Conclusions}

Research activities involving heat transfer at supercritical pressures have attracted attention in recent years because of possibility of increase in thermal output of heat transfer and industrial equipment. Because of high pressure and temperature conditions associated with heat transfer at supercritical pressures, only few experimental heat transfer studies are being carried out at supercritical conditions. The use of numerical tools for heat transfer and other related studies at supercritical pressures is increasing because of the high-pressure-temperature limitation of experimental studies at supercritical conditions. Heat transfer correlations implemented in these numerical tools are used to obtain numerical 
heat transfer data to complement experimental heat transfer data provided through experimental studies. In order to further broaden the understanding of fluid flow and heat transfer, this review examines the performance of heat transfer correlations adopted at supercritical pressures. It is found from the review that most of the correlations could predict heat transfer quite well in the low enthalpy region and few of the correlations could predict heat transfer in the high enthalpy region near critical and pseudo-critical conditions (heat transfer deteriorated conditions). However, no single heat transfer correlation is able to accurately predict all the experimental results presented in this work. The following are other major findings obtained as a result of this review:

1) Some of the heat transfer correlations for predicting heat transfer in upward flows of vertical geometry could also be used for predicting heat transfer in downward flows of vertical geometry. The two different choices of heat transfer correlations could behave closely similar outside the regions of near critical and pseudo-critical points. The correlations of Watts and Chou [48], Jackson [49] and Zhao et al. [15] are explicitly stated in open literature for predicting heat transfer in vertical downward fluid flows. Most of the existing heat transfer correlations are for predicting heat transfer in vertical upward fluid flows.

2) Some of the heat transfer correlations predicted quite well experimental data while others less predicted experimental data at different design parameters and operating conditions. This gives indication that heat transfer at supercritical pressures depends strongly on test geometry and operating conditions.

3) There is no single heat transfer correlation available that could predict experimental data very well within the acceptable error limit over all the experimental operating conditions considered in this study. However, correlations of Jackson [46], Jackson [49], Cheng et al. [39], Zhao et al. [15], Krasnoshchekov-Protopopov [37] [38] and Bishop et al. [40] could perform well in predicting heat transfer for most of the experimental operating conditions associated with the experimental data considered in this study.

4) Among the existing correlations for predicting the onset of heat transfer deterioration HTD presented in this work, correlation of Schatte et al. [53] best predicted the experimental data used for the comparison with all the data points within $\pm 15 \%$ of the experimental data points. Correlations of Styrikovich et al. (1967) and Mokry et al. (2011) also quite well predicted the experimental data. Criterion of Jackson and Hall, or the criterion of Seo et al. was recommended for the determination of onset of HTD due to buoyancy effects or for the flow affected by buoyancy.

The readers of this review would be able to adopt the best performing correlations based on the comparison between the heat transfer correlations and experimental data presented in this work for their future activities involving fluid flow and heat transfer. It is recommended that more experiments on fluid flow and heat transfer at supercritical pressures be carried out to enable validation of similar numerical studies. 


\section{References}

[1] Li, H., Wang, H., Luo, Y., Gu, H., Shi, X., et al. (2009) Experimental Investigation on Heat Transfer from a Heated Rod with a Helically Wrapped Wire inside a Square Vertical Channel to Water at Supercritical Pressures. Nuclear Engineering and Design, 239, 2004-2012. https://doi.org/10.1016/j.nucengdes.2009.05.011

[2] Wang, J., Li, H., Yu, S. and Chen, T. (2011) Comparison of the Heat Transfer Characteristics of Supercritical Pressure Water to That of Subcritical Pressure Water in Vertically-Upward Tubes. International Journal of Multiphase Flow, 37, 769-776. https://doi.org/10.1016/j.ijmultiphaseflow.2011.01.013

[3] Wang, W., Bi, Q., Wang, L., Lv, H. and Leung, L.K.H. (2014) Experimental Investigation of Heat Transfer from a $2 \times 2$ Rod Bundle to Supercritical Pressure Water. Nuclear Engineering and Design, 275, 205-218. https://doi.org/10.1016/j.nucengdes.2014.04.036

[4] Cheng, X. and Schulenberg, T. (2001) Heat Transfer at Supercritical Pressure-Literature Review and Application to an HPLWR. Scientific Rept. FZKA6609, Forschungszentrum Karlsruhe. https://publikationen.bibliothek.kit.edu/270049813/3814083

[5] Pioro, I.L. and Duffey, R.B. (2007) Heat Transfer and Hydraulic Resistance at Supercritical Pressures in Power Engineering Applications. ASME. https://doi.org/10.1115/1.802523

[6] Gupta, S., Saltanov, E., Mokry, S.J., Pioro, I., Trevani, L. and McGillivray, D. (2013) Developing Empirical Heat-Transfer Correlations for Supercritical $\mathrm{CO}_{2}$ Flowing in Vertical Bare Tubes. Nuclear Engineering and Design, 261, 116-131. https://doi.org/10.1016/j.nucengdes.2013.02.048

[7] Mokry, S., Pioro, I., Kirillov, P. and Gospodinov, Y. (2010) Supercritical-Water Heat Transfer in a Vertical Bare Tube. Nuclear Engineering and Design, 240, 568-576. https://doi.org/10.1016/j.nucengdes.2009.09.003

[8] Licht, J.R., Anderson, M.H., Corradini, M.L. and Bonazza, R. (2007) Heat Transfer Phenomena in Supercritical Water Nuclear Reactors. Final Technical Report, DE-FG07-04ID14602.

[9] Licht, J., Anderson, M. and Corradini, M. (2008) Heat Transfer to Water at Supercritical Pressures in a Circular and Square Annular Flow Geometry. International Journal of Heat and Fluid Flow, 29, 156-166. https://doi.org/10.1016/j.ijheatfluidflow.2007.09.007

[10] Jackson, J.D. (2013) Fluid Flow and Convective Heat Transfer to Fluids at Supercritical Pressure. Nuclear Engineering and Design, 264, 24-40. https://doi.org/10.1016/j.nucengdes.2012.09.040

[11] Kim, D.E. and Kim, M.H. (2010) Experimental Study of the Effects of Flow Acceleration and Buoyancy on Heat Transfer in a Supercritical Fluid Flow in a Circular Tube. Nuclear Engineering and Design, 240, 3336-3349. https://doi.org/10.1016/j.nucengdes.2010.07.002

[12] Maitri, R. (2014) A CFD Assisted Control System Design for Supercritical Water Cooled Reactor. Masters' Thesis Submitted to School of Graduate and Postdoctoral Studies, University of Western Ontario, London.

[13] Palko, D. and Anglart, H. (2008) Numerical Study of Heat Transfer Deterioration. Inter-National Students Workshop on High Performance Light Water Reactors (HPLWR), Karlsruhe, 31 March-3 April 2008, 4 p.

[14] Palko, D. and Anglart, H. (2008) Theoretical and Numerical Study of Heat Transfer 
Deterioration in High Performance Light Water Reactor. Science and Technology of Nuclear Installations, 2008, 5 p.

[15] Zhao, M., Gu, H.Y. and Cheng, X. (2014) Experimental Study on Heat Transfer of Supercritical Water Flowing downward in Circular Tubes. Annals of Nuclear Energy, 63, 339-349. https://doi.org/10.1016/j.anucene.2013.07.003

[16] Tom, C. (2014) Literature Study-Convective Heat Transfer to Fluid Operating at a Supercritical Pressure. Report Nr. 00000.

[17] Lei, X., Li, H., Zhang, W., Dinh, N.T., Guo, Y. and Yu, S. (2017) Experimental Study on the Difference of Heat Transfer Characteristics between Vertical and Horizontal Flows of Supercritical Pressure Water. Applied Thermal Engineering, 113, 609-620. https://doi.org/10.1016/j.applthermaleng.2016.11.051

[18] Zhang, L., Liu, M., Dong, Q. and Zhao, S. (2011) Numerical Research of Heat Transfer of Supercritical $\mathrm{CO}_{2}$ in Channels. Energy and Power Engineering, 3, 167-173. https://doi.org/10.4236/epe.2011.32021

[19] Liao, S.M. and Zhao, T.S. (2002) An Experimental Investigation of Convection Heat Transfer to Supercritical Carbon Dioxide in Miniature Tubes. International Journal of Heat and Mass Transfer, 45, 5025-5034.

https://doi.org/10.1016/S0017-9310(02)00206-5

[20] Yamagata, K., Nishikawa, K., Hasegawa, S., Fujii, T. and Yoshida, S. (1972) Forced Convection Heat Transfer to Supercritical Water Flowing in Tubes. International Journal of Heat and Mass Transfer, 15, 2575-2593. https://doi.org/10.1016/0017-9310(72)90148-2

[21] Zhang, G., Zhang, H., Gu, H., Yang, Y. and Cheng, X. (2012) Experimental and Numerical Investigation of Turbulent Convective Heat Transfer Deterioration of Supercritical Water in Vertical Tube. Nuclear Engineering and Design, 248, 226-237. https://doi.org/10.1016/j.nucengdes.2012.03.026

[22] Gu, H.Y., Li, H.B., Hu, Z.X., Liu, D. and Zhao, M. (2015) Heat Transfer to Supercritical Water in a $2 \times 2$ Rod Bundle. Annals of Nuclear Energy, 83, 114-124. https://doi.org/10.1016/j.anucene.2015.04.020

[23] Gu, H.Y., Hu, Z.X., Liu, D., Xiao, Y. and Cheng, X. (2015) Experimental Studies on Heat Transfer to Supercritical Water in $2 \times 2$ Rod Bundle with Two Channels. Nuclear Engineering and Design, 291, 212-223. https://doi.org/10.1016/j.nucengdes.2015.05.028

[24] Gu, H.-Y., Hu, Z.-X., Liu, D., Li, H.-B., Zhao, M. and Cheng, X. (2016) Experimental Study on Heat Transfer to Supercritical Water in $2 \times 2$ Rod Bundle with Wire Wraps. Experimental Thermal and Fluid Science, 70, 17-28. https://doi.org/10.1016/j.expthermflusci.2015.08.015

[25] Duffey, R.B. and Pioro, I.L. (2005) Experimental Heat Transfer of Supercritical Carbon Dioxide Flowing inside Channels (Survey). Nuclear Engineering and Design, 235, 913-924. https://doi.org/10.1016/j.nucengdes.2004.11.011

[26] Pioro, L.I. and Duffey, R.B. (2005) Experimental Heat Transfer in Supercritical Water Flowing inside Channels (Survey). Nuclear Engineering and Design, 235, 2407-2430. https://doi.org/10.1016/j.nucengdes.2005.05.034

[27] Zhu, Y. (2010) Numerical Investigation of the Flow and Heat Transfer within the Core Cooling Channel of a Supercritical Water Reactor. PhD Thesis, Institut für Kernenergetik und Energiesysteme (IKE), Universität Stuttgart, Pfaffenwaldring 31, D-70550 Stuttgart.

[28] Liu, L., Xiao, Z., Yan, X., Zeng, X. and Huang, Y. (2013) Heat Transfer Deterioration to Supercritical Water in Circular Tube and Annular Channel. Nuclear Engi- 
neering and Design, 255, 97-104. https://doi.org/10.1016/j.nucengdes.2012.09.025

[29] Liu, X.J., Yang T. and Cheng, X. (2013) Thermal-Hydraulic Analysis of Flow Blockage in a Supercritical Water-Cooled Fuel Bundle with Sub-Channel Code. Annals of Nuclear Energy, 59, 194-203. https://doi.org/10.1016/j.anucene.2013.03.047

[30] Cheng, X., Kuang, B. and Yang, Y.H. (2007) Numerical Analysis of Heat Transfer in Supercritical Water Cooled Flow Channels. Nuclear Engineering and Design, 237, 240-252. https://doi.org/10.1016/j.nucengdes.2006.06.011

[31] Sharabi, M.B. (2008) CFD Analyses of Heat Transfer and Flow Instability Phenomena Relevant to Fuel Bundles in Supercritical Water Reactors. PhD Thesis Presented to Dipartimento di Ingegneria Meccanica, Nucleare e della Produzione, Università di Pisa.

[32] Wen, Q.L. and Gu, H.Y. (2011) Numerical Investigation of Acceleration Effect on Heat Transfer Deterioration Phenomenon in Supercritical Water. Progress in Nuclear Energy, 53, 480-486. https://doi.org/10.1016/j.pnucene.2011.02.012

[33] Xi, X., Xiao, Z., Yan, X., Li, Y. and Huang, Y. (2013) The Axial Power Distribution Validation of the SCWR Fuel Assembly with Coupled Neutronics-Thermal Hydraulics Method. Nuclear Engineering and Design, 258, 157-163. https://doi.org/10.1016/j.nucengdes.2013.01.031

[34] Huang, D., Wu, Z., Sunden, B. and Li, W. (2016) A Brief Review on Convection Heat Transfer of Fluids at Supercritical Pressures in Tubes and the Recent Progress. Applied Energy, 162, 494-505. https://doi.org/10.1016/j.apenergy.2015.10.080

[35] Gang, W., Pan, J., Bi, Q., Yang, Z. and Wang, H. (2014) Heat Transfer Characteristics of Supercritical Pressure Water in Vertical upward Annuli. Nuclear Engineering and Design, 273, 449-458. https://doi.org/10.1016/j.nucengdes.2014.03.038

[36] Dittus, F.W. and Boelter, L.M.K. (1930) Heat Transfer in Automobile Radiators of the Tubular Type. University of California Press, Berkeley, University of California Publications in Engineering, Vol. 2, 443-461.

[37] Krasnoshchekov, E.A. and Protopopov, V.S. (1959) Heat Transfer at Supercritical Region in Flow of Carbon Dioxide and Water in Tubes. Thermal Engineering, 12, 26-30.

[38] Krasnoshchekov, E.A. and Protopopov, V.S. (1960) About Heat Transfer in Flow of Carbon Dioxide and Water at Supercritical Region of State Parameters. Thermal Engineering, 10, 94.

[39] Cheng, X., Yang, Y.H. and Huang, S.F. (2009) A Simplified Method for Heat Transfer Prediction of Supercritical Fluids in Circular Tubes. Annals of Nuclear Energy, 36, 1120-1128. https://doi.org/10.1016/j.anucene.2009.04.016

[40] Bishop, A.A., Sandberg, R.O. and Tong, L.S. (1964) High Temperature Supercritical Pressure Water Loop: Part IV. Forced Convection Heat Transfer to Water at Near-Critical Temperatures and Super-Critical Pressures. Westinghouse Electric Corporation, Pittsburgh.

[41] Dyadyakin, B.V. and Popov, A.S. (1977) Heat Transfer and Thermal Resistance of Tight Seven-Rod Bundle, Cooled with Water Flow at Supercritical Pressures. Transactions of VTI, No. 11, 244-253. (In Russian)

[42] Ornatsky, A.P., Glushchenko, L.P., Siomin, E.T., et al. (1970) The Research of Temperature Conditions of Small Diameter Parallel Tubes Cooled by Water under Supercritical Pressures. In: Proceedings of the 4th International Heat Transfer Conference, Vol. 4, Elsevier Publ. Company, Paris, B 8.11. 
[43] Shitsman, M.W. (1974) Heat Transfer to Supercritical Helium, Carbon Dioxide, and Water: Analysis of Thermodynamic and Transport Properties and Experimental Data. Cryogenics, 14, 77-83. https://doi.org/10.1016/0011-2275(74)90242-2

[44] Griem, H. (1996) A New Procedure for the Prediction of Forced Convection Heat Transfer at Near- and Supercritical Pressure. Heat and Mass Transfer, 31, 301-305. https://doi.org/10.1007/BF02184042

[45] Mokry, S., Pioro, I, Farah, A., King, K., Gupta, S., et al. (2011) Development of Supercritical Water Heat-Transfer Correlation for Vertical Bare Tubes. Nuclear Engineering and Design, 241, 1126-1136. https://doi.org/10.1016/j.nucengdes.2010.06.012

[46] Jackson, J.D. (2002) Consideration of the Heat Transfer Properties of Supercritical Pressure Water in Connection with the Cooling of Advanced Nuclear Reactors. Proceedings of the 13th Pacific Basin Nuclear Conference, Shenzhen, 21-25 October 2002, 8 p.

[47] Herkenrath, H., Mörk-Mörkenstein, P., Jung, U. and Weckermann, F.J. (1967) Wärmeübertragung an Wasser bei erzwungener Strömung im Druckbereich von 140 bis 250 bar, EUR 3658d, Euratom.

[48] Watts, M.J. and Chou, C.T. (1982) Mixed Convection Heat Transfer to Supercritical Pressure Water. Proceedings of the 4th International Heat Transfer Conference, München, Vol. 3, 495-500.

[49] Jackson, J.D. (2010) An Extended Model of Variable Property Developing Mixed Convection Heat Transfer in Vertical Tubes. Proceedings of the 1 st Meeting of International Specialists on Supercritical Pressure Heat Transfer and Fluid Dynamics, Pisa, 5-8 July 2010, 9 p.

[50] McAdams, W.H., Kennel, W.E. and Addoms, J.N. (1950) Heat Transfer to Superheated Steam at High Pressures. Transactions of ASME, 72, 421-428.

[51] Zahlan, H., Groeneveld, D.C. and Tavoularis, S. (2010) Look-Up Table for Trans-Critical Heat Transfer. Proceedings of the 2nd Canada-China Joint Workshop on Supercritical Water-Cooled Reactors, Toronto, 25-28 April 2010, 18 p.

[52] Zahlan, H., Groeneveld, D.C., Tavoularis, S., Mokry, S. and Pioro, I. (2011) Assessment of Supercritical Heat Transfer Prediction Methods. Proceedings of the 5 th International Symposium on SCWR, Vancouver, 13-16 March 2011, Paper P008, 20 p.

[53] Schatte, G.A., Kohlhepp, A., Wieland, C. and Spliethoff, H. (2016) Development of a New Empirical Correlation for the Prediction of the Onset of the Deterioration of Heat Transfer to Supercritical Water in Vertical Tubes. International Journal of Heat and Mass Transfer, 102, 133-141. https://doi.org/10.1016/j.ijheatmasstransfer.2016.06.007

[54] Vikhrev, Y.V., Barulin, Y.D. and Kon’Kov, A.S. (1967) A Study of Heat Transfer in Vertical Tubes at Supercritical Pressures. Thermal Engineering, 14, 116-119.

[55] Styrikovich, M.A., Margulova, T.K. and Miropol'skii, Z.L. (1967) Problems in the Development of Designs of Supercritical Boilers. Thermal Engineering, 14, 5-9.

[56] Li, Z., Zhang, D., Wu, Y., Lu, J. and Liu, Q. (2014) A New Criterion for Predicting Deterioration of Heat Transfer to Supercritical Water in Smooth Tubes. Proceedings of the Chinese Society of Electrical Engineering, 34, 6304-6309.

[57] Kondrat'ev, N.S. (1969) Heat Transfer and Hydraulic Resistance with Supercritical Water Flowing in Tubes. Thermal Engineering, 16, 73-77.

[58] Protopopov, V.S., Kuraeva, I.V. and Antonov, A.M. (1973) An Approach to the Determination of the Conditions of Occurrence of Deteriorated Heat Transfer Re- 
gimes at Supercritical Pressures. High Temperature, 11, 529-532.

[59] Petukhov, B.S., Kurganov, V.A. and Ankudinov, V.B. (1983) Heat Transfer and Flow Resistance in the Turbulent Pipe-Flow of a Fluid with Near-Critical State Parameters. High Temperature, 21, 92-100.

[60] Haaland, S.E. (1983) Simple and Explicit Formulas for the Friction Factor in Turbulent Flow. Journal of Fluids Engineering, 103, 89-90. https://doi.org/10.1115/1.3240948

[61] Xiong, T., Yan, X., Huang, S., Yu, J. and Huang, Y. (2013) Modeling and Analysis of Supercritical Flow Instability in Parallel Channels. International Journal of Heat and Mass Transfer, 57, 549-557. https://doi.org/10.1016/j.ijheatmasstransfer.2012.08.046

[62] Su, Y., Feng, J., Zhao, H., Tian, W., Su, G. and Qiu, S. (2013) Theoretical Study on the Flow Instability of Supercritical Water in the Parallel Channels. Progress in Nuclear Energy, 68, 169-176. https://doi.org/10.1016/j.pnucene.2013.06.005

[63] IAEA TECDOC-1746, 2014. Heat Transfer Behaviour and Thermohydraulics Code Testing for SCWRs. IAEA TECDOC Series, IAEA-TECDOC-1746, September, Vienna, Austria, 496 p.

http://www-pub.iaea.org/MTCD/Publications/PDF/TE-1746_web.pdf 


\section{Nomenclature}

The Dimensionless numbers, Greek letters, Symbols and Subscripts adopted in the assessment of heat transfer correlations include:

\section{Dimensionless Numbers}

Gr Grashof number, $G r_{B}=\frac{g \cdot \rho_{B} \cdot d^{3} \cdot\left(\rho_{B}-\rho_{w}\right)}{\mu_{B}^{2}} ; \overline{G r}$ Averaged Grashof number, $\overline{G r_{b}}=\frac{g \cdot \rho_{b} \cdot d^{3} \cdot\left(\rho_{b}-\bar{\rho}\right)}{\mu_{b}^{2}} ; N u$ Nusselt number $[h d / \lambda] ; \operatorname{Pr}$ Prandtl number [ $\mu C_{p} / \lambda$ ]; Re Reynolds number $[G D / \mu$ ]; and $\overline{P r}$ Average cross-sectional Prandtl number $\left[\mu \bar{C}_{p} / \lambda\right]$.

\section{Greek Letters}

$\lambda$ Thermal conductivity $[\mathrm{W} /(\mathrm{m} \cdot \mathrm{K})] ; \mu$ Dynamic viscosity $[\mathrm{kg} /(\mathrm{m} \cdot \mathrm{s})] ; v$ Kinematic viscosity, $v=\mu / \rho\left[\mathrm{m}^{2} / \mathrm{s}\right] ; \rho$ Density of a fluid $\left[\mathrm{kg} / \mathrm{m}^{3}\right] ; \quad \bar{\rho}$ Average density, $\left(\rho_{w}+\rho_{b}\right) / 2\left[\mathrm{~kg} / \mathrm{m}^{3}\right] ; \xi$ Friction factor; $\beta$ Thermal expansion coefficient $[1 / \mathrm{K}] ; \pi_{A}$ Dimensionless parameter, representing acceleration effect, $\pi_{A}=\frac{q \cdot \beta_{B}}{G \cdot C_{p . B}}$; and $\pi_{B}$ Dimensionless parameter, representing buoyancy effect, $\pi_{B}=\frac{q \cdot \beta_{B} \cdot d}{\lambda_{B}}$.

\section{Symbols}

Bo Dimensionless parameter, representing buoyancy effect; $C_{p}$ Specific heat capacity $[\mathrm{J} /(\mathrm{kg} \cdot \mathrm{K})] ; \bar{C}_{p}$ Average specific heat, $\frac{H_{w}-H_{b}}{T_{w}-T_{b}},[\mathrm{~J} /(\mathrm{kg} \cdot \mathrm{K})] ; D, d$ Diameter [m]; $D_{h p} D_{h}$ Hydraulic diameter [m]; $G$ Mass flux $\left[\mathrm{kg} /\left(\mathrm{m}^{2} \mathrm{~s}\right)\right] ; g$ Gravitational acceleration $\left[\mathrm{m} / \mathrm{s}^{2}\right] ; H, h$ Specific enthalpy $[\mathrm{J} / \mathrm{kg}] ; H T C, h$ Heat transfer coefficient $\left[\mathrm{W} /\left(\mathrm{m}^{2} / \mathrm{K}\right)\right] ; P$ Pressure $[\mathrm{Pa}] ; Q, Q^{\prime \prime}, q$ Heat flux $\left[\mathrm{W} / \mathrm{m}^{2}\right] ; T$ Temperature [K]; $t$ Time [second]; and $x, l$ axial location [m].

\section{Subscripts}

$a v e, v$ average; $B, b$ Bulk; $c r$, crit Value at critical point; $D B$ Dittus-Boelter; $e X$ exit; $f$ fluid; in inlet; out outlet; $p c$ Pseudo-critical; $w$ Wall. 